\title{
Expression and Activation of Mitogen-activated Protein Kinases in Matured Porcine Oocytes under Thermal Stress
}

\author{
Shih-Ying YEN1), Jung-Kai TSENG ${ }^{1-3)}$, Show-Mei CHUANG4), Shuen-Ei CHEN1) and \\ Jyh-Cherng JU1, 5-8)

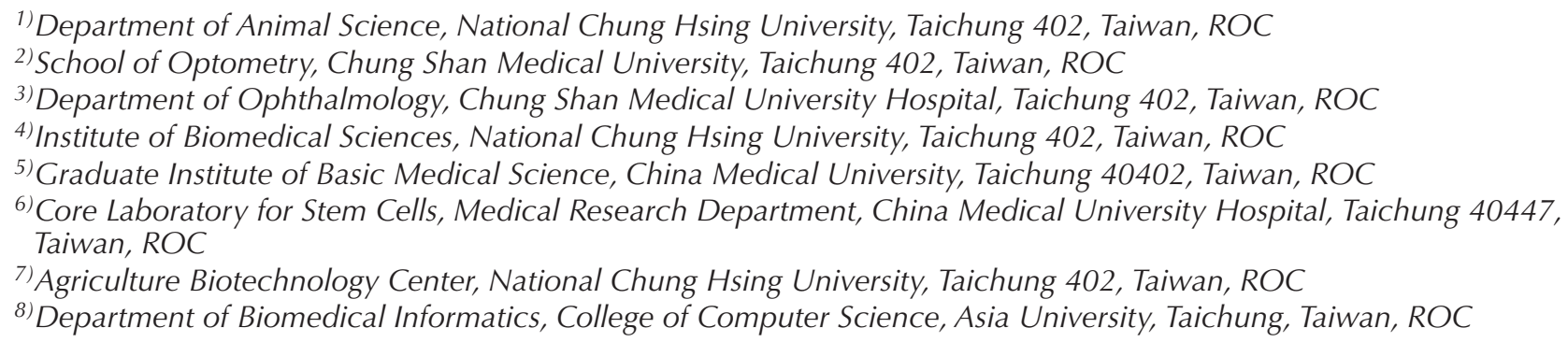

\begin{abstract}
In this study, we determined the expression and activation of p38 MAPK in matured porcine oocytes subjected to heat shock (HS). When MII oocytes were heated, only the phosphorylated p38 levels relative to the total p38 levels decreased $(\mathrm{P}<0.01)$ after HS, but no clear relationship with HS treatments was observed in the ERK, JNK and p90 ${ }^{\text {rsk }}$ expressions of matured oocytes. To confirm p38 activation in matured oocytes, immunocytochemical staining was performed to localize its expression and distribution in the ooplasm, and the results were largely consistent with previous Western blot analyses. Moreover, when matured oocytes were co-cultured with a P38 MAPK inhibitor, SB203580, for $4 \mathrm{~h}$ at $41.5 \mathrm{C}$, the activation of its immediate downstream substrate MAPKAPK-2 was not inhibited within any of the treatment groups. It appears that the MAPKAPK2 levels increased only under prolonged culture (HS4h and C4h) compared with the control group. In conclusion, p38 activity in porcine oocytes was decreased after exposure to HS and prolonged culture. These alterations of p38 and activation of MAPKAPK2 may be associated with porcine oocyte viability under HS conditions, and a potential cross-talk between p38 MAPK and other signaling cascades may exist, which warrants additional investigation.
\end{abstract}

Key words: Heat shock, MAPKAP2, Oocyte, p38, Pig

(J. Reprod. Dev. 60: 388-394, 2014)

$\mathbf{E}$ evated ambient temperatures have long been recognized as a major cause of reduced reproductive performance in domestic livestock during hot seasons in tropical and subtropical areas [1]. Similar seasonal or environmental effects on birth defects are also identified in humans [2]. Although the underlying mechanisms causing low embryo survival and conception rates are not fully understood, based on in vitro studies, temperature elevation retards embryo development and alters the morphologies of nuclei and cytoskeletons of mammalian oocytes [3, 4].

Fully grown mammalian oocytes are arrested at the prophase of the first meiotic division, which is termed the germinal vesicle (GV) stage. In response to the physiologic LH surge, the oocyte undergoes GV breakdown (GVBD), extrudes the first polar body, and proceeds into metaphase II (MII); at that point, it undergoes second meiotic

Received: January 18, 2014

Accepted: June 30, 2014

Published online in J-STAGE: August 4, 2014

(C)2014 by the Society for Reproduction and Development

Correspondence: J-C Ju (e-mail: jcju@dragon.nchu.edu.tw)

This is an open-access article distributed under the terms of the Creative Commons Attribution Non-Commercial No Derivatives (by-nc-nd) License

$<$ http://creativecommons.org/licenses/by-nc-nd/3.0/>. arrest until fertilized by sperm or activated by other stimuli. Signal transduction within oocytes is mostly via activation or deactivation of specific protein kinases by phosphorylation or dephosphorylation; these are among the most important mechanisms regulating meiosis. These processes are largely controlled by various kinase molecules, such as maturation promoting factor (MPF) and mitogen-activated protein kinases (MAPKs) [5, 6]. Activation of MPF enables eukaryotic cells to enter into metaphase [7]. Extracellular signal-regulated kinases (ERK1 and ERK2), which are members of the canonical MAPK family, are activated in response to various extracellular signaling molecules, notably growth factors, via an upstream small G-protein Ras. In addition, Jun kinases (JNK) and p38, collectively known as stress-activated protein kinases (SAPKs) constitute two other kinase families, which are also induced by extracellular cues [8,9]. These signaling pathways play critical roles in regulation and determination of cell growth, proliferation, differentiation, and/or apoptosis under physiologic and stress conditions. However, their functions and activation profiles during oocyte development are largely unknown. Nevertheless, p38 has been associated with various cellular stress responses, e.g., hyperosmolarity, ultraviolet radiation, inflammatory cytokines and endotoxins. In that regard, p38 is released in response to various physiologic cues, including growth factors, mitogens and 
FSH. Furthermore, it is also involved in various processes during differentiation, proliferation, and survival of somatic cell lineages $[10,11]$. It appears that $\mathrm{p} 38$ in porcine oocytes is activated around GVBD and remains active at and throughout the MI-MII transitional stage (Yen et al., unpublished data). The objective of the current study was to determine the expression and activation of p38 and other MAPKs after in vitro maturation (IVM) of porcine oocytes, with or without exposure to external heat shock (HS).

\section{Materials and Methods}

\section{Oocyte collection and IVM}

Porcine ovaries were stored in saline (35-37 C) and transported to the laboratory in an insulated container within $1 \mathrm{~h}$ after slaughter. Cumulus-oocyte complexes (COCs) were collected by aspirating ovarian surface follicles ( 3 to $6 \mathrm{~mm}$ in diameter). The recovered COCs were then matured $(20$ to $30 \mathrm{COCs} / 100 \mu \mathrm{l})$ in North Carolina State University-23 (NCSU-23) medium supplemented with 10\% follicular fluid, cysteine $(0.1 \mathrm{mg} / \mathrm{mL}, \mathrm{C}-5182$, Sigma-Aldrich, St. Louis, MO, USA), EGF (10 ng/ml, E-4127, Sigma-Aldrich) and gonadotropins (hCG, $10 \mathrm{IU} / \mathrm{ml}$, Sigma-Aldrich, A; PMSG, $10 \mathrm{IU} / \mathrm{ml}$, Sigma-Aldrich) for the first $22 \mathrm{~h}$ of culture at $39 \mathrm{C}$ in an incubator containing $5 \% \mathrm{CO}_{2}$ in air [12]. Thereafter, medium was replaced with gonadotropin-free NCSU-23 medium, and the oocytes were cultured continuously for another $20 \mathrm{~h}$ prior to HS treatment. Matured oocytes were selected by visualization of polar body extrusion at 42 $\mathrm{h}$ after the onset of IVM [13]

\section{Treatments with HS and kinase inhibitor SB203580}

Matured oocytes were randomly allocated to three HS groups and two control groups. In the former, oocytes were subjected to $41.5 \mathrm{C}$ for 1,2 or $4 \mathrm{~h}$, whereas in the latter, oocytes were cultured at $39 \mathrm{C}$ for $0(\mathrm{COh})$ or $4 \mathrm{~h}(\mathrm{C} 4 \mathrm{~h})$ without $\mathrm{HS}$, as described previously $[3,14]$. Inhibition of p38 was done with $10 \mu \mathrm{M}$ of SB203580 (Calbiochem; San Diego, CA, USA), a specific inhibitor for $\mathrm{p} 38$, added to the IVM medium at various stages of culture.

\section{Western blotting}

Analysis of protein expression was conducted as described previously [15], and the following antibodies were purchased from Santa Cruz Biotechnology Inc., CA, USA, unless mentioned otherwise. Briefly, oocytes were rinsed in DPBS-PVA immediately after treatments and then collected in sodium dodecyl sulfate (SDS) sample buffer containing $100 \mathrm{mM}$ Tris/ $\mathrm{HCl}$ (pH 6.8), 5\% 2-mercaptoethanol, $3 \%$ SDS, $4 \%$ glycerol and $0.1 \%$ bromophenol blue. All samples (50-150 oocytes per sample) were boiled for $5 \mathrm{~min}$ and stored at -80 C. Oocyte samples were subjected to electrophoresis in $10 \%$ (V/V) polyacrylamide/SDS gels $[15,16]$. The resolved proteins were transferred to nitrocellulose membranes, which were blocked with $10 \%$ chicken serum in TBS $(20 \mathrm{mM}$ Tris- $\mathrm{HCl}, \mathrm{pH} 7.4,150 \mathrm{mM} \mathrm{NaCl})$ containing $0.1 \%$ Tween 20 for $1 \mathrm{~h}$ and then incubated with rabbit polyclonal anti-phospho-p38 MAPK (1:100, \#9211), anti-phosphoERK (1:500, \#9101), anti-phospho-JNK (1:100, \#9251) antibodies or rabbit polyclonal anti-human p38 (1:200, C-20), anti-ERK (1:500, K-23), anti-JNK (1:500, \#9252) and mouse monoclonal anti-RSK antibodies $(1: 100, \mathrm{E}-1)$ at $4 \mathrm{C}$ overnight. Membranes were washed three times (10 min/each) with TBST (20 mM Tris, PH 7.4, $500 \mathrm{mM}$ $\mathrm{NaCl}, 0.05 \%$ Tween-20) and then incubated with secondary antibody (1:10000, anti-rabbit immunoglobulin horseradish peroxidase) for 1 $\mathrm{h}$ at room temperature. After three washes for $10 \mathrm{~min}$ each, proteins were detected with a Super ${ }^{\circledR}$ Signal West Pico Chemiluminrescent Substrate Kit (Pierce Biotechnology, Inc., Rockford, IL, USA). The intensity of each band was measured by using densitometry (Scion Image software for Windows).

\section{Immunocytochemical staining}

Oocytes were washed twice in DPBS-PVA and then fixed in DPBS-PVA containing 4\% paraformaldehyde and $0.2 \%$ Triton X-100 for $40 \mathrm{~min}$ at room temperature. Thereafter, fixed samples were washed twice in DPBS-PVA for $15 \mathrm{~min}$ and stored overnight in $1 \%$ BSA in DPBS-PVA (BSA-DPBS-PVA) at $4 \mathrm{C}$ prior to staining. The next day, oocytes were blocked with $10 \%$ goat serum (Dako A/S, Glostrup, Denmark) in DPBS-PVA-BSA for 45 min and then incubated in DPBS-PVA-BSA containing rabbit polyclonal antiphospho-p38 antibody (1:100, \#9211, Santa Cruz Biotechnology) at $4 \mathrm{C}$ overnight. After three washes in PBS-PVA-BSA, oocytes were incubated in DPBS-PVA-BSA containing Alexa Fluor 488-labeled goat anti-rabbit IgG (1:300; Molecular Probes Inc., Eugene, OR, USA) for $40 \mathrm{~min}$ at room temperature, and then the chromosomes were stained with Hoechst 33342 (10 $\mu \mathrm{g} / \mathrm{ml}$, Sigma-Aldrich). Negative control images were obtained by omitting the first antibody during staining. Following a complete washing, oocytes were mounted on slides with mounting medium (50\% DPBS, 50\% Glycerol, $25 \mathrm{mg} / \mathrm{ml}$ $\mathrm{NaN}_{3}$ ) and observed under an Olympus epifluorescence microscope (AX-70). The intensity of p-p38 expression in oocytes was analyzed with the ImageJ software [17].

\section{Experimental designs}

Experiment 1- Expression and activation of MAPKs in matured oocytes after HS: For an initial screening of matured oocytes, three members of the MAPK family, i.e., ERK, JNK and p38 MAPK and their related downstream molecules, were examined.

After $42 \mathrm{~h}$ of IVM, cumulus cells were removed from COCs, and matured oocytes were randomly allocated to five treatment groups, i.e., two control groups ( $\mathrm{C} 0 \mathrm{~h}$ and $\mathrm{C} 4 \mathrm{~h}, 39 \mathrm{C}$ ) and three HS groups (HS1h, HS2h or HS4h, at 41.5 C) for analyses by Western blotting.

Experiment 2- Subcellular localization of phosphorylated p38 of matured oocytes: Based on the observations in Experiment 1, confirmation of activated p-p38 in matured porcine oocytes was performed by immunocytochemistry to visualize its expression and distribution in heat-shocked (at 41.5 C for 1, 2 and $4 \mathrm{~h}$ ) oocytes, with non-heat-shocked (39 C) oocytes being used for comparison. Oocytes were stained with Hoechst stain and the secondary antibody but without the primary antibody to serve as the negative control. The fluorescence intensity was further quantified using the ImageJ software for analysis.

Experiment 3-Detection of $\mathrm{p} 38$ downstream MAPKAPK2 expression under HS conditions: The p38 inhibitor, SB203580 $(10 \mu \mathrm{M})$, was added to the IVM medium during the culture period; thereafter, matured oocytes were fixed and stained for determination of nuclear status. To determine whether HS-influenced activation of MAPKAPK2 is mediated by p38 in matured porcine oocytes, denuded MII oocytes 


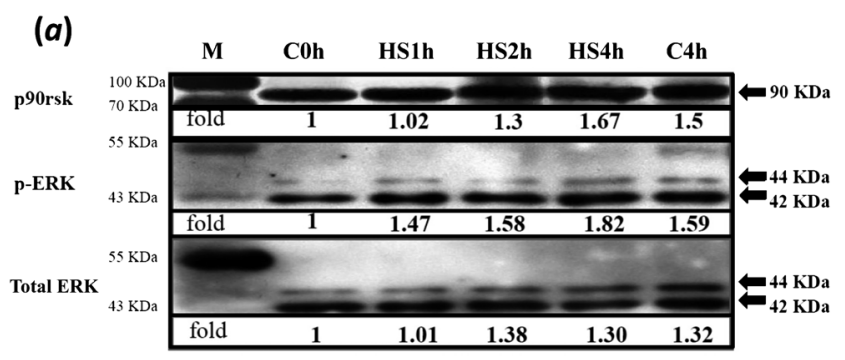

(b)

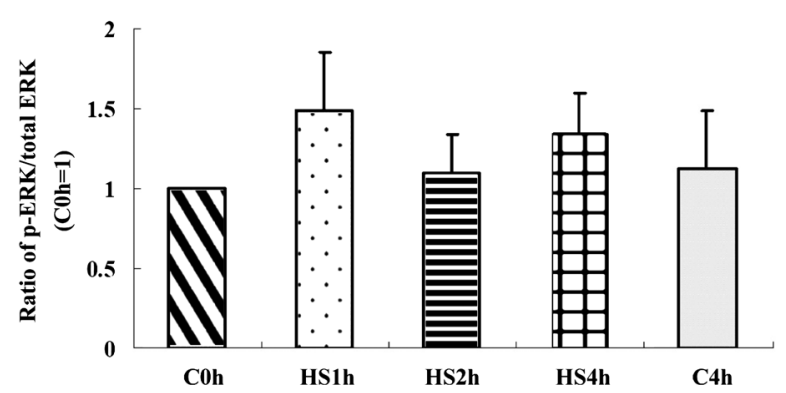

Fig. 1. Expressions of ERK and its downstream p90rsk in matured porcine oocytes after in vitro heat shock at $41.5 \mathrm{C}$ for $0,1,2$ or 4 h. (a) A representative immunoblot of p-ERK, total ERK (44 and $42 \mathrm{kDa}$, respectively) and p90rsk (upper panel, $90 \mathrm{kDa}$ ). There were no significant differences among treatment groups. $(b)$ There was no significant difference among treatment groups in relative activity of ERK (p-ERK/total ERK). Data are expressed as folds of the $\mathrm{C} 0 \mathrm{~h}$ group. Each lane of the SDS-PAGE gels contained 50 oocytes (four replicates). Bars indicate means \pm SEM. M, marker.

were randomly cultured with or without SB203580 in the $\mathrm{C} 4 \mathrm{~h}, \mathrm{C} 0 \mathrm{~h}$, HS1h, HS2h or HS4h groups and then collected for phosphorylated MAPKAP2 analysis by Western blotting.

\section{Statistical analyses}

All data from Western blotting and immunocytochemical staining were analyzed by ANOVA using the General Linear Model (GLM) procedure in the Statistical Analysis System software [18] and then subjected to Tukey's test. Percentile data were analyzed by Chi-square. For all statistical analyses, significance was set at $\mathrm{P}<0.05$.

\section{Results}

\section{Experiment 1: Expression and activation of MAPKs in matured oocytes after HS}

With various durations of HS treatment, activation of ERK1/2 and its downstream target molecules, p90rsk and JNK, in matured oocytes was not significantly different among treatment groups (Figs. 1 and 2). However, the total p38 levels in all treatments (including the $\mathrm{C} 4 \mathrm{~h}$ group) were increased $(\mathrm{P}<0.05)$ compared with in the control $(\mathrm{C} 0 \mathrm{~h})$ group (Fig. 3a). In contrast, its relative activities (p-p38/total p38) were significantly reduced throughout the time courses of the HS (HS1h, HS2h and HS4h) and prolonged culture (C4h) groups, with no significant differences among them compared with the $\mathrm{COh}$ group (Fig. 3). Similarly, the p-p38 signal was clearly reduced in

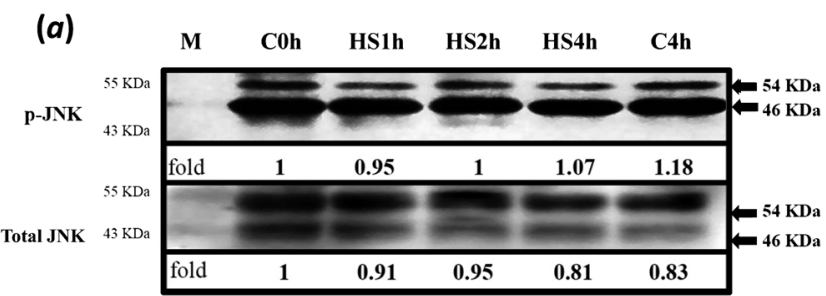

(b)

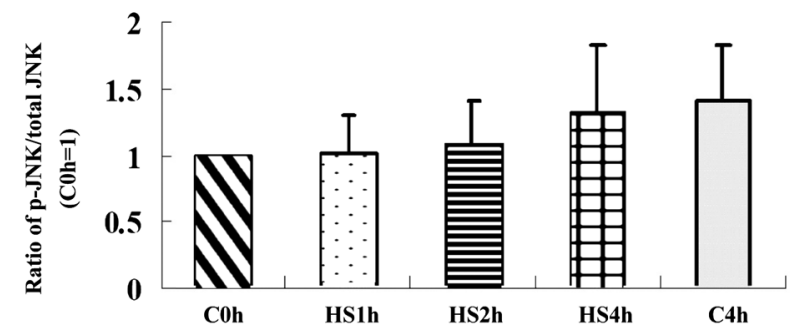

Fig. 2. Expression of JNK in matured porcine oocytes after in vitro heat shock at $41.5 \mathrm{C}$ for $0,1,2$ or $4 \mathrm{~h}$. (a) A representative immunoblot of JNK (upper panel) and total JNK (lower panel, 54 and 46 $\mathrm{kDa}$, respectively). There were no significant differences among treatment groups in either panel. Data are expressed as folds of the COh group. Each lane of the SDS-PAGE gel contained 100 oocytes (four replicates). Bars indicate means \pm SEM. M, marker.
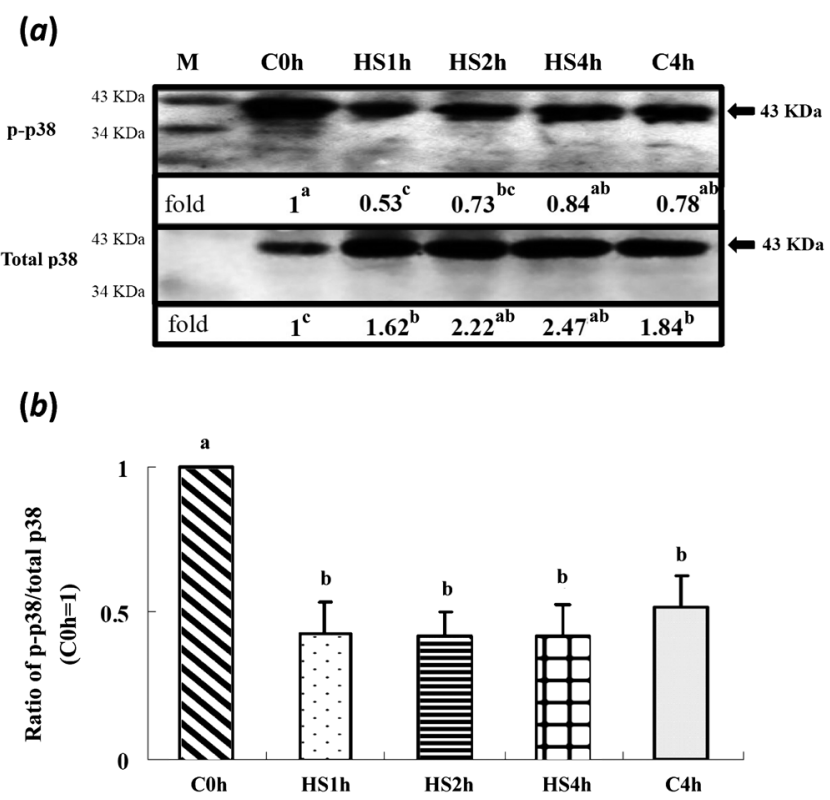

Fig. 3. Level of p-p38 in matured porcine oocytes in control (non-heatshocked group; maintained at $39 \mathrm{C}$ ) and heat-shocked (HS, $41.5 \mathrm{C}$ ) groups. (a) Representative immunoblot of p-p38 (upper panel) and total p38 (lower panel, $43 \mathrm{kDa}$ ). The p-p38 activity was decreased $(\mathrm{P}<0.05)$ in the HS1h group and then slightly rebounded as the duration of HS increased. The total p38 level was increased when the duration of HS was prolonged $(\mathrm{P}<0.05)$. (b) The relative activities of p-p38 in all the HS groups were reduced $(\mathrm{P}<0.05)$ compared with the $\mathrm{C} 0 \mathrm{~h}$ group. Each lane of the SDS-PAGE gel contained 150 oocytes (five replicates). ${ }^{\mathrm{a}, \mathrm{b}}$ Bars without a common superscript differed $(\mathrm{P}<0.05)$. Bars indicate means \pm SEM. M, marker. 

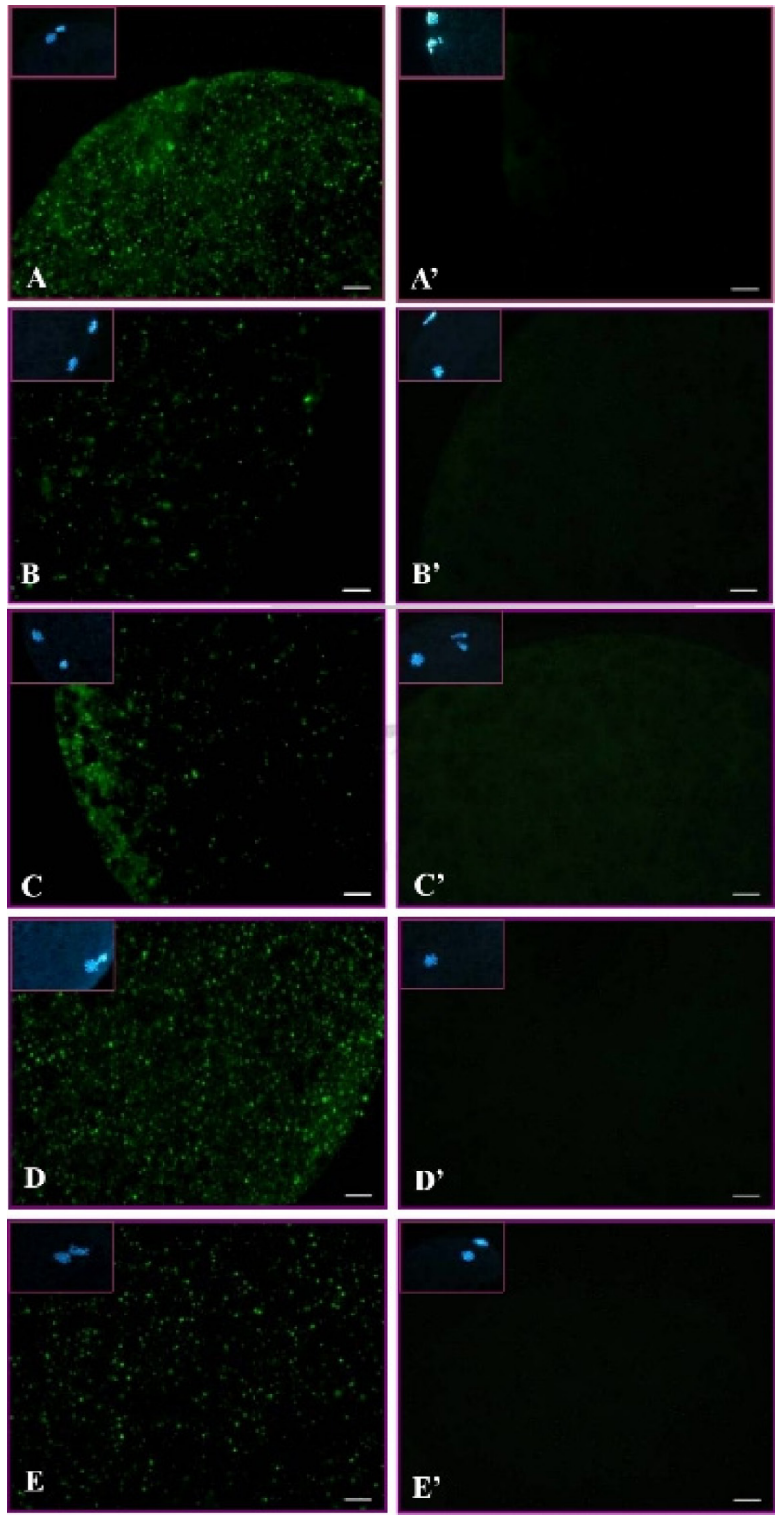

Fig. 4. Subcellular localization of p-p38 in matured porcine oocytes in the non-heat-shocked $(39 \mathrm{C})$ and heat-shocked $(41.5 \mathrm{C})$ groups. Green dots are p-p38 labeled by immunocytochemical staining. (A-E) Expressions of p-p38 in matured oocytes after heat shock for $0 \mathrm{~h}(\mathrm{~A}), 1 \mathrm{~h} \mathrm{(B),} 2 \mathrm{~h}(\mathrm{C})$ or $4 \mathrm{~h}(\mathrm{D})$ and the p-p38 level in matured oocytes cultured at $39 \mathrm{C}$ for $4 \mathrm{~h}(\mathrm{E})$. Panels A'-E' are negative controls (without primary antibody), and insets are chromatin/chromosome (blue) structures stained by Hoechst 33342. Scale bar, $10 \mu \mathrm{m}$.

the HS1h group (Fig. 4B) compared with those in the HSOh (Fig. 4A), HS2h (Fig. 4C), HS4h (Fig. 4D) and C4h (Fig. 4E) groups. The p-p38 activity, quantified by the intensity of immunocytochemical staining, of matured porcine oocytes was significantly decreased in (a)

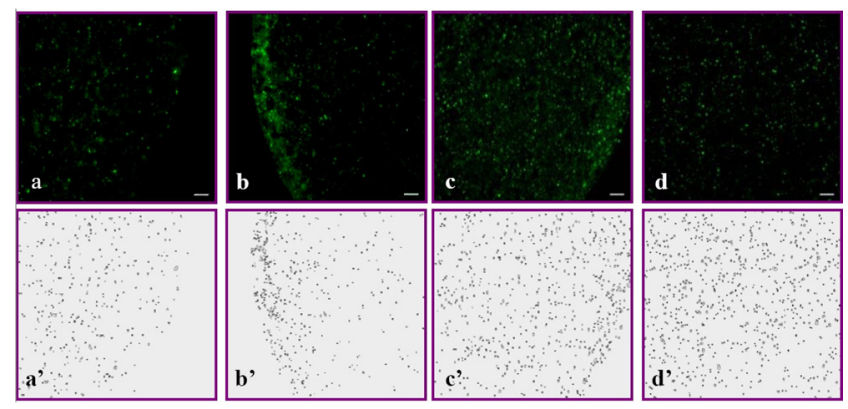

(b)

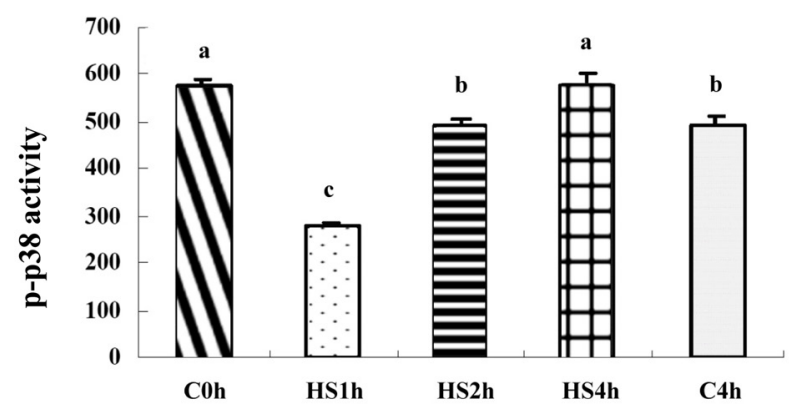

Fig. 5. Quantification of p-p38 activity in matured porcine oocytes after heat shock (HS, 41.5 C). (a) a-d, p-p38 levels in matured oocytes after HS for $1 \mathrm{~h}$ (HS1h, a), $2 \mathrm{~h}$ (HS2h, b) or $4 \mathrm{~h}$ (HS4h, c) and oocytes cultured at $39 \mathrm{C}$ for $4 \mathrm{~h}(\mathrm{C} 4 \mathrm{~h}, \mathrm{~d})$. Panels a'-d' show the p-p38 levels quantified by the ImageJ software. (b) The intensity of p-p38 decreased in the HS1h group and then increased in the HS2h or HS4h groups after prolonged HS $(\mathrm{P}<0.05)$. ${ }^{\mathrm{a}-\mathrm{c}}$ Bars without a common superscript differed $(\mathrm{P}<0.05)$. Bars indicate means \pm SEM (five replicates, five oocytes/replicate).

the HS1h group but subsequently recovered in the HS2h, HS4h and prolonged culture (C4h) groups (Fig. 5).

\section{Experiment 2: Subcellular localization of phosphorylated p38} in matured oocytes

The expression and distribution of p-p38 in matured porcine oocytes after HS (41.5 C) were visualized, and the results are shown in Fig. 4. A normal matured oocyte (without HS, $39 \mathrm{C}$ ) has a homogeneous distribution of p-p38 throughout the ooplasm. In the heat-shocked groups, p-p38 first reduced in the HS1h group and then largely recovered in both the prolonged $\mathrm{HS}$ ( $\mathrm{H} 2 \mathrm{~h}$ and $\mathrm{H} 4 \mathrm{~h})$ and culture (C4h) group as expressed by the immunocytochemical localization and its fluorescence intensity when analyzed by ImageJ (Fig. 5).

\section{Experiment 3: Detection of p38 downstream MAPKAPK2} expression under HS conditions

As shown in Fig. 6, when denuded matured oocytes were cocultured with SB203580 and then subjected to HS at 41.5 C for various periods of time, the expression of phosphorylated MAPKAPK-2 (an immediate downstream molecule of p38) was not inhibited in any of the HS and C4h groups and only increased under the prolonged cultured conditions regardless of treatment with the inhibitor. Expression of 


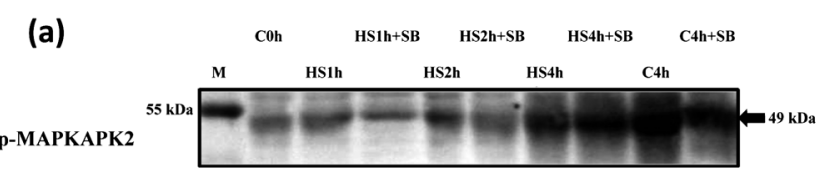

(b)

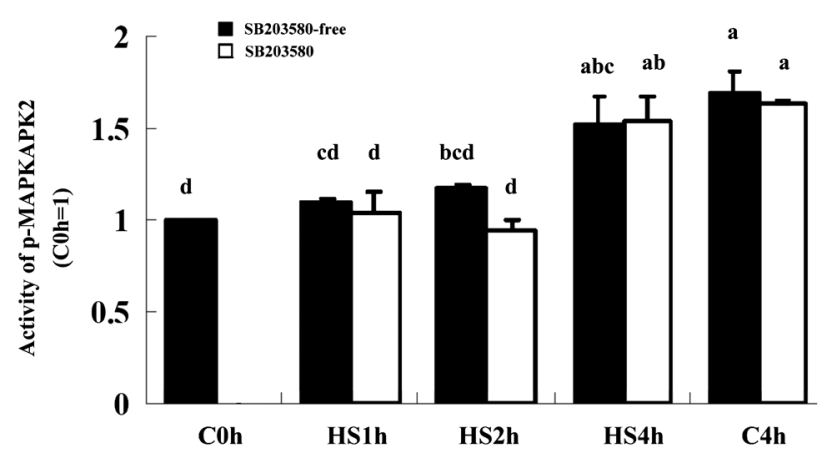

Fig. 6. Expression of p-MAPKAPK2 in matured porcine oocytes cocultured with SB203580 under HS $(41.5 \mathrm{C})$ conditions. (a) A representative immunoblot of p-MAPKAPK2 $(49 \mathrm{kDa})$ derived from matured oocytes cultured in $10 \mu \mathrm{M}$ SB203580 plus HS conditions for various durations. (b) Expression of p-MAPKAPK2 was increased depending on HS duration in SB203580-free groups but was generally increased under the prolonged culture conditions, especially in the HS4h and C4h groups, which show significantly higher intensities than the COh group when the intensity of each band was analyzed by the ImageJ software. Five replicates were performed and each lane of the SDS-PAGE gel contained 150 oocytes. ${ }^{a, b, c, d} \mathrm{P}<0.05$. Bars indicate means \pm SEM. M, marker.

p-MAPKAPK2 was only significantly increased in the HS4h and $\mathrm{C} 4 \mathrm{~h}$ groups compared with the control $(\mathrm{COh})$.

\section{Discussion}

It is well known that p38 MAPK is one of the mitogen-activated protein kinases that are associated with cellular responses stimulated by stresses, cytokines, HS, osmotic shock and radiation and are mainly involved in cell differentiation and apoptosis. Although MAPKs have been implicated in oocyte maturation in several species (Xenopus, [19]; mice, [6]; pigs, Yen et al., unpublished data), there is very limited information regarding the role of $\mathrm{p} 38$ in HS-induced signaling in oocytes of domestic livestock [20]. This study is apparently the first report regarding the role of p38 in matured porcine oocytes subjected to HS.

In mammalian cells, the p38 pathway is activated by various stresses or agonists, e.g., tyrosine kinase or cytokine receptor activators [21]. It is likely that there are multiple cellular sensing mechanisms and that their signals eventually converge to the p38 signaling pathway, although no specific membrane receptors for heat have been reported. Heat, UV light and osmotic stimuli can trigger hydrolysis of membrane sphingomyelins by sphingomyelinase which in turn increases cellular ceramide, a second messenger, to activate SAPKs
$[22,23]$. Also, Jun kinases and apoptosis signal-regulating kinase-1 (ASK1), an upstream molecule of p38, were found to be associated with regulation of apoptosis in somatic cells [24]. Based on our immunocytochemical assay, activation of p38 decreased only in the HS1h group, although it subsequently rebounded when in vitro HS was prolonged. Therefore, we inferred that the apoptotic pathway might have been initiated due to the long duration of HS. This was entirely consistent with our previous studies, in which we detected a drastic reduction in developmental competence of embryos subjected to $>2 \mathrm{~h}$ of in vitro HS $[13,14,25]$. It has also been reported that apoptosis of bovine oocytes can be induced by in vitro HS [26, 27], one of the severe cellular stresses that has been shown to cause embryonic loss to occur in vitro $[3,25,28]$ and possibly in vivo [29]. However, the molecular and cellular bases of heat-induced cell injuries, particularly the deleterious effects of HS on oocyte or embryo viability, remain poorly understood.

Alternatively, short-term mild HS conditions could enhance thermotolerance of various types of cells, organisms and even mammalian embryos $[30,31]$. However, the mode of how it is triggered may be important. For instance, transient activation of JNK or p38 (or both) is usually associated with cell survival or differentiation, whereas sustained activation of these kinases caused apoptosis [32-34]. Based on previous reports, HS may desensitize the 38 pathway, and the desensitization kinetics may be associated with development of thermotolerance in some organisms $[35,36]$. In addition, HS-induced p38 desensitization was reported to be closely related to heat-induced thermotolerance in Chinese hamster cells [35]. Based on our kinase assays, when matured oocytes were heated or prolonged cultured, the relative activity of p38 was drastically decreased compared with in the control groups (Fig. 3). However, we could not completely exclude the possibility that along with an extended duration of HS or in vitro culture, oocytes may be physiologically adaptive or dysfunctional in terms of the reduction of the relative $\mathrm{p} 38$ activity over time. The existence of the confounding effects of heat shock with a prolonged culture period may not be overlooked, although a mild short-term heat shock could enhance the physiologic parameters (such as intracellular calcium concentrations) or metabolic responses of oocytes or embryos [37, 38]. Conversely, direct HS applied to MII oocytes had no immediate influences in the HS and control groups on activation of p90rsk, ERK and JNK (Fig. 1). Consequently, oocytes became apoptotic under longer HS conditions, at least partially due to no significant activation of the ERK signaling pathway, which has a potential role in mediating cell division, migration and survival.

Activation of the $\mathrm{p} 38$ pathway can also promote phosphorylation of small heat shock protein 27 (Hsp27) [35, 39-41], which is catalyzed by MAPKAPK2, a serine-protein kinase immediately downstream from $\mathrm{p} 38$ [40, 42]. Activation of Hsp27 stabilizes cellular actin filaments during environmental insults and mediates dynamic changes in actin filaments in response to p38 activation. [43-46]. In the present study (Experiment 3), treatment with SB203580 under HS conditions failed to alter MAPKAPK2 activation, and the phosphorylated MAPKAPK2 activity decreased after a short period of HS, although it finally (and unexpectedly) rebounded under prolonged HS and culture conditions (Fig 6, P < 0.05). Induction of thermotolerance with a parallel increase of Hsps was found to 
inhibit heat-induced apoptosis in many cell types [47-50]. However, when the concentration of Hsp27 was abnormally elevated, it caused erroneous actin polymerization, leading to cell blebbing or apoptosis [51]. We therefore reasoned that the increased MAPKAPK2 activity might have caused the elevation of Hsp27/25, which, in turn, could have initiated apoptosis under the extended HS conditions. Given the increased MAPKAPK2 activity during the prolonged HS and even when matured oocytes were incubated with the kinase inhibitor, it seemed that there may be different upstream activators or alternative pathways in addition to 38 signaling. Murai et al. [52] also reported that a short-term stress-hypersensitive $\mathrm{PC} 12 \mathrm{~m} 3$ mutant cell induced p38 activation, whereas prolonged stress induced activation of JNK. However, the responsiveness of these kinases under HS mainly depended on the cell types.

In this study, we demonstrated that p38 was the only MAPK examined that responded to the HS signal of matured oocytes. We inferred that spatial and temporal alteration of $\mathrm{p} 38$ activation appeared to regulate HS-induced signaling of matured porcine oocytes and that apoptosis might be amplified depending on the p38 MAPK/ MAPKAPK2 signaling cascades. However, the changes in the developmental competence of matured porcine oocytes in relation to their apoptotic gene expression after HS require further investigation.

\section{Acknowledgments}

This study was partly supported by grants from China Medical University Hospital (DRM-103-104) and the National Science Council (NSC 95-2313-B-005-034- MY3, 98-2628-B-005-019MY3 and 101-2313-B-039-010-MY3), Executive Yuan, Taiwan, and the Ministry of Education, Taiwan, Republic of China, under the ATU plan. We are also grateful to Dr John Kastelic, a professor at the University of Calgary, Canada, for critical reading and suggestions related to this manuscript.

\section{References}

1. Cavestany D, el-Wishy AB, Foote RH. Effect of season and high environmental temperature on fertility of Holstein cattle. J Dairy Sci 1985; 68: 1471-1478. [Medline] [CrossRef]

2. Hwang BF, Magnus P, Jaakkold JK. Seasonal variation pf birth defects in Norway. Biomedicine 2013; 3: 95-101. [CrossRef]

3. Tseng JK, Chen CH, Chou PC, Yeh SP, Ju JC. Influences of follicular size on parthenogenetic activation and in vitro heat shock on the cytoskeleton in cattle oocytes. Reprod Domest Anim 2004; 39: 146-153. [Medline] [CrossRef]

4. Ju JC, Jiang S, Tseng JK, Parks JE, Yang X. Heat shock reduces developmental competence and alters spindle configuration of bovine oocytes. Theriogenology 2005; 64 : 1677-1689. [Medline] [CrossRef]

5. Masui Y, Markert CL. Cytoplasmic control of nuclear behavior during meiotic maturation of frog oocytes. J Exp Zool 1971; 177: 129-145. [Medline] [CrossRef]

6. Sobajima T, Aoki F, Kohmoto K. Activation of mitogen-activated protein kinase during meiotic maturation in mouse oocytes. J Reprod Fertil 1993; 97: 389-394. [Medline] [CrossRef]

7. Gautier J, Norbury C, Lohka M, Nurse P, Maller J. Purified maturation-promoting factor contains the product of a Xenopus homolog of the fission yeast cell cycle control gene cdc2 $2^{+}$Cell 1988; 54: 433-439. [Medline] [CrossRef]

8. Lewis TS, Shapiro PS, Ahn NG. Signal transduction through MAP kinase cascades. $A d v$ Cancer Res 1998; 74: 49-139. [Medline] [CrossRef]

9. Cobb MH. MAP kinase pathways. Prog Biophys Mol Biol 1999; 71: 479-500. [Medline] [CrossRef]

10. Woodgett JR, Avruch J, Kyriakis J. The stress activated protein kinase pathway. Cancer Surv 1996; 27: 127-138. [Medline]

11. Nebreda AR, Porras A. p38 MAP kinases: beyond the stress response. Trends Biochem
Sci 2000; 25: 257-260. [Medline] [CrossRef]

12. Abeydeera LR, Wang WH, Cantley TC, Rieke A, Prather RS, Day BN. Presence of epidermal growth factor during in vitro maturation of pig oocytes and embryo culture can modulate blastocyst development after in vitro fertilization. Mol Reprod Dev 1998; 51: 395-401. [Medline] [CrossRef]

13. Ju JC, Tsay C, Ruan CW. Alterations and reversibility in the chromatin, cytoskeleton and development of pig oocytes treated with roscovitine. Mol Reprod Dev 2003; 64: 482-491. [Medline] [CrossRef]

14. Ju JC, Tseng JK. Nuclear and cytoskeletal alterations of in vitro matured porcine oocytes under hyperthermia. Mol Reprod Dev 2004; 68: 125-133. [Medline] [CrossRef]

15. Tseng JK, Tang PC, Ju JC. In vitro thermal stress induces apoptosis and reduces development of porcine parthenotes. Theriogenology 2006; 66: 1073-1082. [Medline] [CrossRef]

16. Laemmli UK. Cleavage of structural proteins during the assembly of the head of bacteriophage T4. Nature 1970; 227: 680-685. [Medline] [CrossRef]

17. Rasband WS, Image JUS. National Institutes of Health. Bethesda, Maryland, USA 2006.

18. SAS Institute SAS User's Guide Statistics, Version 6.03, SAS. Institute Inc., Cary, NC, USA, 2002.

19. Gotoh Y, Nishida E, Matsuda S, Shiina N, Kosako H, Shiokawa K, Akiyama T, Ohta $\mathbf{K}$, Sakai $\mathbf{H}$. In vitro effects on microtubule dynamics of purified Xenopus M phaseactivated MAP kinase. Nature 1991; 349: 251-254. [Medline] [CrossRef]

20. Inoue M, Naito K, Aoki F, Toyoda Y, Sato E. Activation of mitogen-activated protein kinase during meiotic maturation in porcine oocytes. Zygote 1995; 3: 265-271. [Medline] [CrossRef]

21. Villa-Diaz LG, Miyano T. Activation of p38 MAPK during porcine oocyte maturation Biol Reprod 2004; 71: 691-696. [Medline] [CrossRef]

22. Widmann C, Gibson S, Jarpe MB, Johnson GL. Mitogen-activated protein kinase: conservation of a three-kinase module from yeast to human. Physiol Rev 1999; 79: 143-180. [Medline]

23. Ruvolo PP. Ceramide regulates cellular homeostasis via diverse stress signaling pathways. Leukemia 2001; 15: 1153-1160. [Medline] [CrossRef]

24. Hannun YA, Obeid LM. Principles of bioactive lipid signalling: lessons from sphingolipids. Nat Rev Mol Cell Biol 2008; 9: 139-150. [Medline] [CrossRef]

25. Ichijo H, Nishida E, Irie K, ten Dijke P, Saitoh M, Moriguchi T, Takagi M, Matsumoto K, Miyazono K, Gotoh Y. Induction of apoptosis by ASK1, a mammalian MAPKKK that activates SAPK/JNK and p38 signaling pathways. Science 1997; 275: 90-94. [Medline] [CrossRef]

26. Ju JC, Parks JE, Yang X. Thermotolerance of IVM-derived bovine oocytes and embryos after short-term heat shock. Mol Reprod Dev 1999; 53: 336-340. [Medline] [CrossRef]

27. Roth Z, Hansen PJ. Involvement of apoptosis in disruption of developmental competence of bovine oocytes by heat shock during maturation. Biol Reprod 2004; 71: 1898-1906. [Medline] [CrossRef]

28. Roth Z, Hansen PJ. Disruption of nuclear maturation and rearrangement of cytoskeletal elements in bovine oocytes exposed to heat shock during maturation. Reproduction 2005 129: 235-244. [Medline] [CrossRef]

29. Edwards JL, Hansen PJ. Differential responses of bovine oocytes and preimplantation embryos to heat shock. Mol Reprod Dev 1997; 46: 138-145. [Medline] [CrossRef]

30. Ealy AD, Drost M, Hansen PJ. Developmental changes in embryonic resistance to adverse effects of maternal heat stress in cows. J Dairy Sci 1993; 76: 2899-2905. [Medline] [CrossRef]

31. Ryan DP, Blakewood EG, Lynn JW, Munyakazi L, Godke RA. Effect of heat-stress on bovine embryo development in vitro. J Anim Sci 1992; 70: 3490-3497. [Medline]

32. Aréchiga CF, Ealy AD, Hansen PJ. Evidence that glutathione is involved in thermotolerance of preimplantation murine embryos. Biol Reprod 1995; 52: 1296-1301. [Medline] [CrossRef]

33. Guo YL, Baysal K, Kang B, Yang LJ, Williamson JR. Correlation between sustained c-Jun N-terminal protein kinase activation and apoptosis induced by tumor necrosis factoralpha in rat mesangial cells. J Biol Chem 1998; 273: 4027-4034. [Medline] [CrossRef]

34. Roulston A, Reinhard C, Amiri P, Williams LT. Early activation of c-Jun N-terminal kinase and $\mathrm{p} 38$ kinase regulate cell survival in response to tumor necrosis factor alpha. $J$ Biol Chem 1998; 273: 10232-10239. [Medline] [CrossRef]

35. Lin FL, Hsu JL, Chou CH, Wu WJ, Chang CI, Liu HJ. Activation of p38 MAPK by damnacanthal mediates apoptosis in SKHep 1 cells through the DR5/TRAIL and TNFR1 TNF- $\alpha$ and p53 pathways. Eur J Pharmacol 2011; 650: 120-129. [Medline] [CrossRef]

36. Landry J, Chrétien P, Laszlo A, Lambert H. Phosphorylation of HSP27 during development and decay of thermotolerance in Chinese hamster cells. J Cell Physiol 1991; 147 93-101. [Medline] [CrossRef]

37. Dorion S, Bérubé J, Huot J, Landry J. A short lived protein involved in the heat shock sensing mechanism responsible for stress-activated protein kinase 2 (SAPK2/p38) activation. J Biol Chem 1999; 274: 37591-37597. [Medline] [CrossRef]

38. Tseng JK, Ju JC. Calcium release of heat-shocked porcine oocytes induced by thimero- 
sal or inositol 1,4,5-trisphosphate (IP3). Anim Reprod Sci 2009; 111: 41-53. [Medline] [CrossRef]

39. Tseng JK, Liu HK, Lin TA, Yang CR, Yang X, Ju JC. Calcium release and development of heat-shocked porcine oocytes after nucleus-ooplasm reconstruction. Cloning Stem Cells 2009; 11: 557-563. [Medline] [CrossRef]

40. Chrétien P, Landry J. Enhanced constitutive expression of the $27-\mathrm{kDa}$ heat shock proteins in heat-resistant variants from Chinese hamster cells. J Cell Physiol 1988; 137: 157-166. [Medline] [CrossRef]

41. Huot J, Lambert H, Lavoie JN, Guimond A, Houle F, Landry J. Characterization of 45-kDa/54-kDa HSP27 kinase, a stress-sensitive kinase which may activate the phosphorylation-dependent protective function of mammalian 27-kDa heat-shock protein HSP27. Eur J Biochem 1995; 227: 416-427. [Medline] [CrossRef]

42. Shin JK, Jeong YT, Jo HC, Kang MY, Chang IS, Baek JC, Park JK, Lee SA, Lee JH, Choi WS, Paik WY. Increased interaction between heat shock protein 27 and mitogenactivated protein kinase (p38 and extracellular signal-regulated kinase) in pre-eclamptic placentas. J Obstet Gynaecol Res 2009; 35: 888-894. [Medline] [CrossRef]

43. Rouse J, Cohen P, Trigon S, Morange M, Alonso-Llamazares A, Zamanillo D, Hunt T, Nebreda AR. A novel kinase cascade triggered by stress and heat shock that stimulates MAPKAP kinase-2 and phosphorylation of the small heat shock proteins. Cell 1994; 78 : 1027-1037. [Medline] [CrossRef]

44. Lavoie JN, Lambert H, Hickey E, Weber LA, Landry J. Modulation of cellular thermoresistance and actin filament stability accompanies phosphorylation-induced changes in the oligomeric structure of heat shock protein 27. Mol Cell Biol 1995; 15: 505-516. [Medline]
45. Guay J, Lambert H, Gingras-Breton G, Lavoie JN, Huot J, Landry J. Regulation of actin filament dynamics by p38 map kinase-mediated phosphorylation of heat shock protein 27. J Cell Sci 1997; 110: 357-368. [Medline]

46. Landry J, Huot $\mathbf{J}$. Regulation of actin dynamics by stress-activated protein kinase 2 (SAPK2)-dependent phosphorylation of heat-shock protein of $27 \mathrm{kDa}$ (Hsp27). Biochem Soc Symp 1999; 64: 79-89. [Medline]

47. Schäfer C, Clapp P, Welsh MJ, Benndorf R, Williams JA. HSP27 expression regulates CCK-induced changes of the actin cytoskeleton in CHO-CCK-A cells. Am J Physiol 1999; 277: C1032-C1043. [Medline]

48. Mosser DD, Martin LH. Induced thermotolerance to apoptosis in a human T lymphocyte cell line. J Cell Physiol 1992; 151: 561-570. [Medline] [CrossRef]

49. Buzzard KA, Giaccia AJ, Killender M, Anderson RL. Heat shock protein 72 modulates pathways of stress-induced apoptosis. J Biol Chem 1998; 273: 17147-17153. [Medline] [CrossRef]

50. Mosser DD, Caron AW, Bourget L, Meriin AB, Sherman MY, Morimoto RI, Massie B. The chaperone function of hsp70 is required for protection against stress-induced apoptosis. Mol Cell Biol 2000; 20: 7146-7159. [Medline] [CrossRef]

51. Deschesnes RG, Huot J, Valerie K, Landry J. Involvement of p38 in apoptosis-associated membrane blebbing and nuclear condensation. Mol Biol Cell 2001; 12: 1569-1582. [Medline] [CrossRef]

52. Murai H, Hiragami F, Kawamura K, Motoda H, Koike Y, Inoue S, Kumagishi K, Ohtsuka A, Kano Y. Differential response of heat-shock-induced p38 MAPK and JNK activity in PC12 mutant and PC12 parental cells for differentiation and apoptosis. Acta Med Okayama 2010; 64: 55-62. [Medline] 